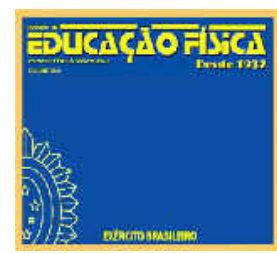

Revisão / Review

\title{
Efeito da melatonina exógena no estresse oxidativo provocado pelo exercício físico
}

\section{Effect of Exogenous Melatonin on the Exercise Induced Oxidative Stress}

Coutinho e Stocchero 


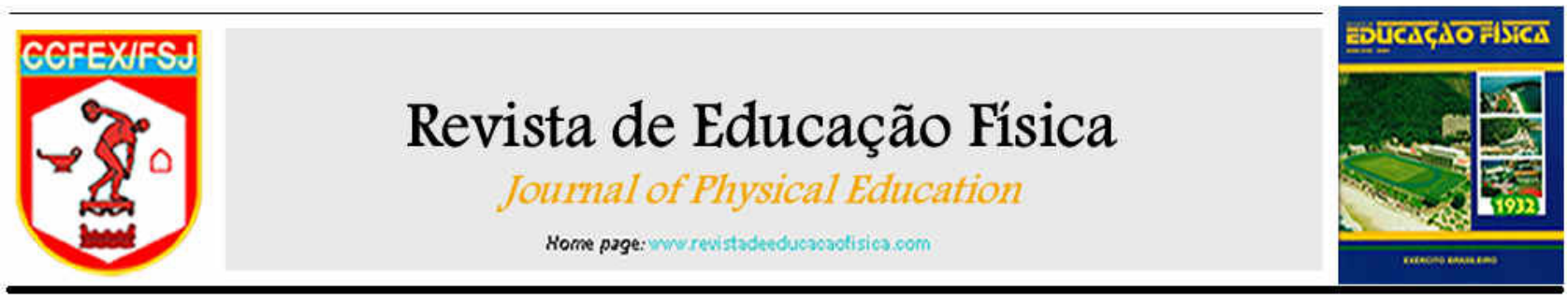

Revisão

Review

\title{
Efeito da melatonina exógena no estresse oxidativo provocado pelo exercício físico
}

\section{Effect of Exogenous Melatonin on the Exercise Induced Oxidative Stress}

\author{
Claudia Coutinho ${ }^{\S 1}$ MD Esp; Cintia Mussi Alvim Stocchero ${ }^{2} \mathrm{PhD}$
}

Recebido em: 03 de junho de 2017. Aceito em: 11 de junho de 2017.

Publicado online em: 30 de junho de 2017.

\section{Resumo}

Introdução: Na prática desportiva competitiva, pesquisadores da fisiologia humana buscam novas descobertas, tanto no campo do treinamento físico como na suplementação de substâncias que possam contribuir para uma melhora do desempenho esportivo, diminuindo a fadiga e contribuindo para a recuperação. Recentemente, a melatonina tem sido alvo de pesquisas por apresentar propriedades que modulam processos celulares intimamente ligados à produção de energia e apresentar propriedades antioxidativas.

Objetivo: Avaliar como a suplementação de melatonina pode atenuar o dano oxidativo da célula induzido pelo exercício.

Métodos: Nesta revisão narrativa, foram consultadas as bases na literatura PubMed e Elsevier, utilizando os termos "melatonin AND oxidative stress in exercise", "melatonin AND exercise performance", "melatonin supplementation AND exercise", desde o ano 2000 até 2016.

Resultados e Discussão: Seis estudos de desenho experimental

\begin{tabular}{|l|}
\hline - A melatonina possui \\
propriedades antioxidantes. \\
Produzida pela glândula pineal \\
também pode ser \\
suplementada exogenamente. \\
- A melatonina promove \\
redução do estresse oxidativo \\
causado pelo exercício físico. \\
- A melatonina diminui o dano \\
celular, promovendo a saúde de \\
atletas de alto rendimento. \\
\hline
\end{tabular}
fizeram parte desta revisão. A melatonina foi suplementada antes do esforço físico e os parâmetros bioquímicos foram mensurados antes, durante e depois do mesmo. Os estudos apontaram diminuição dos marcadores de estresse oxidativo utilizando-se melatonina. Todavia, há controvérsias quanto à utilização dos reagentes laboratoriais para esses marcadores.

Conclusão: A literatura mostra que a suplementação de melatonina promove melhora no padrão oxidativo a partir da diminuição dos níveis de marcadores da oxidação no sangue e nos tecidos. Tal suplementação mostrouse benéfica e segura para atletas que, devido às altas cargas de treinamento físico, estão cronicamente expostos a ataques mais severos do estresse oxidativo pelo exercício.

Palavras-chave: melatonina, antioxidante, radicais livres, espécies reativas de oxigênio.

\begin{abstract}
Introduction: In competitive sport, researchers in human physiology seek new discoveries, both in the field of physical training and in the supplementation of substances that can contribute to an improvement in sports performance, reducing fatigue and contributing to recovery. Recently, melatonin has been subject of research because of its modulating actions in cellular processes, closely linked to the production of energy and because of its antioxidative properties.
\end{abstract}

\footnotetext{
${ }^{\S}$ Autor correspondente: Claudia Coutinho-e-mail: dra.claudiacoutinho@gmail.com. Afiliações: ${ }^{1}$ Escola de Educação Física do Exército; ${ }^{2}$ Instituto Federal de Educação, Ciência e Tecnologia do Rio Grande do Sul (IFRS/RS/Brasil).
} 
Objective: To evaluate how melatonin supplementation can attenuate cellular oxidative stress induced by exercise.

Methods: In this narrative review, searches in the literature were performed in PubMed and Elsevier bases using the terms "melatonin AND oxidative stress in exercise"; "melatonin AND exercise performance"; "melatonin supplementation AND exercise", from 2000 to 2016.

Results and Discussion: Six experimental studies were part of this review. Melatonin was supplemented before physical exertion and the biochemical parameters were measured before, during and after the exercise test. The studies indicated a decrease in the markers of oxidative stress using melatonin. However, there are controversies regarding the use of laboratory reagents for those markers.

Conclusion: The literature shows that melatonin supplementation promotes improvement in the oxidative pattern by decreasing levels of oxidation markers in blood and tissues. Such supplementation has proved to be beneficial and safe for athletes who, due to the high loads of physical training, are chronically exposed to more severe attacks of oxidative stress related to exercise.

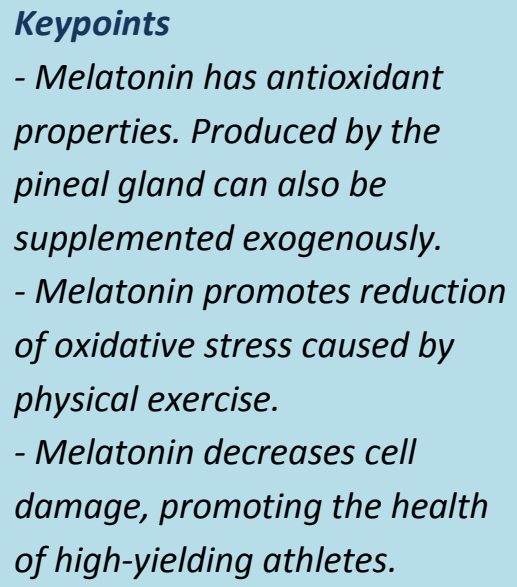

Keywords: melatonin, antioxidant, free radicals, reactive oxygen species.

\section{Efeito da melatonina exógena no estresse oxidativo provocado pelo exercício físico}

\section{Introdução}

O exercício físico provoca um aumento na demanda da produção de energia e da atividade cardíaca a fim de realizar o trabalho musculoesquelético. Durante o exercício, a célula muscular passa a consumir uma taxa maior de oxigênio para a produção de adenosina trifosfato na mitocôndria, gerando espécies reativas de oxigênio: os radicais livres. Os radicais livres, originados com o consumo de oxigênio, colocam a célula em risco e causam dano mitocondrial por meio do estresse oxidativo(1). $\mathrm{O}$ termo estresse oxidativo foi definido, pela primeira vez, em 1985(2), esse fenômeno ocorre quando o equilíbrio entre os radicais livres e o sistema de defesa antioxidante da célula fica prejudicado(3). A célula possui um sistema de defesa contra esse ataque oxidativo, por meio de uma cascata antioxidante, que inclui uma série de compostos como catalase, superóxido dismutase (SOD) e glutationa peroxidase (GPX), entre outros(4). Além dessa defesa celular contra a oxidação, o corpo humano possui também outros mecanismos de defesa humorais. 
série de antioxidantes após administração da melatonina(8). Ao reagir com os radicais livres na célula, a melatonina dá origem a metabólitos que possuem atividade sequestradora de radicais livres, amplificando sua ação e formando uma cascata de elementos antioxidantes(8). Alguns autores demostraram que o exercício provoca um aumento na liberação de melatonina pela glândula pineal, observado por meio da elevação de seus níveis plasmáticos, levando a um incremento no efeito antioxidante. Tal efeito foi observado tanto em modelo humano(9) quanto em modelo animal(10).

A suplementação de melatonina pode atenuar o dano oxidativo da célula induzido pelo exercício, através da maior disponibilidade de antioxidantes durante a produção de energia, o que se faz pela mensuração bioquímica de compostos utilizados como marcadores do estresse oxidativo, em amostras de sangue, urina e tecidos. $\mathrm{O}$ incremento no efeito antioxidante pode promover efeitos benéficos ao organismo durante a prática desportiva, por atenuar o dano mitocondrial e, possivelmente, diminuir o dano muscular e a fadiga, contribuindo para melhora do desempenho físico.

O objetivo desta revisão foi avaliar como a suplementação de melatonina pode atenuar o dano oxidativo da célula induzido pelo exercício.

\section{Métodos}

Artigo de revisão narrativa, no qual foram consultadas as bases de dados Pubmed e Elsevier. Os descritores desta busca foram "melatonin AND oxidative stress in exercise", "melatonin AND exercise performance", e "melatonin supplementation AND exercise".

Os critérios de inclusão foram: estudos publicados entre os anos de 2000 e 2016, que tivessem correlacionado a suplementação de melatonina em humanos com respostas endógenas, hormonais ou moleculares, ligadas ao estresse oxidativo causado pelo exercício físico. Foram incluídos, também, estudos em modelo animal visando estabelecer a base bioquímica do efeito modulador da melatonina sobre os radicais livres.

\section{Lista de Abreviaturas e Bioquímica}

6-sulfatoximelatonina - metabólito da melatonina

8-OhdG - 8-hidroxi 2- desoxiguanosina

DNA - ácido desoxirribonucleico

GPX - glutationa peroxidase

GSH - glutationa reduzida

GSSD - glutationa oxidada

GSSD/GSH - relação glutationa oxidada sobre glutationa reduzida

MDA - malondialdeído

MPO-mieloperoxidase

$\mathbf{N}$-acetil-5-metoxitriptamina melatonina

$\mathbf{R N A}_{m}$ - ácido ribonucleico mensageiro

RONS - reactive oxygen and nitrogen

species: espécies reativas de oxigênio e

nitrogênio

ROS - reactive oxygen species: espécies

reativas de oxigênio

SOD - superóxido dismutase

TAS - total antioxidant status: estado

total de antioxidantes

TBARS - substâncias reativas de

fenobarbitúricos

Os critérios de exclusão foram: 1) Estudos de revisão de literatura; 2) Estudos que não relacionaram a melatonina diretamente com o dano oxidativo, tanto através do exercício físico, como através de algum estímulo oxidante no caso dos estudos em modelo animal; 3) Estudos que não mensuraram o efeito da administração de melatonina no estresse oxidativo.

Para análise dos artigos, os mesmos foram separados em estudos com humanos e estudos em modelo animal. Nos estudos em humanos, foram pesquisados o tipo e a duração do exercício-teste, a maneira como foi feita a suplementação com a melatonina, e foram avaliados os parâmetros laboratoriais utilizados como marcadores do estresse oxidativo. A partir daí, foram observados os resultados na tentativa de correlacionar a atenuação do dano oxidativo com a 
administração de melatonina antes do exercício físico.

Nos estudos que utilizaram modelo animal, foram pesquisados três diferentes fatores de estresse oxidativo e relacionados com a suplementação de melatonina. Os marcadores da oxidação celular foram mensurados em três diferentes locais: cérebro, fígado e músculo cardíaco. Desta forma, pôde-se observar a penetração e o efeito da melatonina em diferentes tecidos

Os artigos de revisão, mencionados nas referências, foram utilizados para explicar o comportamento da melatonina frente à exigência oxidativa durante o exercício.

\section{Resultados e Discussão}

A Figura 1 apresenta o fluxograma dos resultados de busca e seleção dos artigos. No descritor " melatonin AND oxidative stress in exercise" foram encontrados 29 artigos. Depois de aplicada a limitação da data de publicação, restaram 24 artigos. Na busca de "melatonin AND exercise performance" foram encontrados 48 artigos e aplicado o filtro da data de publicação, restando 40 artigos. Quando procurado o descritor "melatonin supplementation AND exercise" foram obtidos 19 artigos. Após a filtragem por ano de publicação, restaram 16 artigos.



Figura 1 - Fluxograma dos artigos utilizados nesta revisão. 
Filtrando apenas artigos originais, restaram somente oito publicações (ensaios clínicos e estudos em modelo animal). Ao serem aplicados os demais critérios de exclusão, um artigo foi retirado por não relacionar a melatonina diretamente com o dano oxidativo e outro foi retirado por não mensurar o efeito da administração de melatonina no estresse oxidativo. Assim, restaram apenas seis artigos: três estudos experimentais em humanos e três estudos experimentais utilizando modelo animal. Os resultados mostraram que houve associação da suplementação de melatonina com melhora no padrão oxidativo $(\mathrm{p}<0,05)$ tanto em modelos humanos como em modelos animais (Tabelas 1 e 2).

Em todos os estudos que fizeram parte das análises, foram utilizados marcadores bioquímicos sintetizados, por meio da sinalização dos radicais livres produzidos durante dos radicais livres produzidos durante o exercício físico.

A Tabela 1 apresenta os estudos, os principais métodos e análises utilizados na suplementação de melatonina, realizados em modelos humanos, todos do tipo ensaio clínico randomizado.

O exercício físico, cronicamente, gera adaptações na plasticidade mitocondrial, na síntese proteica e na tolerância aos radicais livres. O termo estresse oxidativo traduz o desequilíbrio pro e antioxidativo na célula sugerindo um descontrole da sinalização redutora(11). Isso se deve à inabilidade do organismo de eliminar as espécies reativas de oxigênio e nitrogênio podendo levar a instalação de apoptose com necrose tecidual e consequente inflamação, decorrente do dano na fibra muscular. A produção de radicais livres parece solicitar uma resposta antioxidante por parte do organismo(11).

Tabela 1 - Estudos em humanos

\begin{tabular}{|c|c|c|c|c|c|c|c|}
\hline Autore ano & Tipo de estudo & Amostra & $\begin{array}{l}\text { Tipo de } \\
\text { Suplementação }\end{array}$ & $\begin{array}{l}\text { Tipo de } \\
\text { Exercício }\end{array}$ & $\begin{array}{l}\text { Parâmetros de } \\
\text { estresse } \\
\text { oxidativo }\end{array}$ & Coleta & Resultados \\
\hline $\begin{array}{l}\text { Maldonado } \\
\text { M D et al., } \\
2012(3)\end{array}$ & $\begin{array}{l}\text { Artigo Original } \\
\text { Randomizado } \\
\text { duplo cego }\end{array}$ & $\begin{array}{l}16 \text { jogadores } \\
\text { profissionais de } \\
\text { futebol entre } 18 \text { e } \\
20 \text { anos. }\end{array}$ & $\begin{array}{l}\text { GM -Melatonina } 6 \mathrm{mg} \\
30 \text { min antes do } \\
\text { exercicio } \\
\text { GC-placebo }\end{array}$ & $\begin{array}{l}-60 \mathrm{~min} \text { exercicio } \\
\text { intenso ( } 135 \mathrm{bpm} \text { ) } \\
\text { cicloergômetro } \\
\text { velocidade média } \\
\text { de } 25 \mathrm{~km} / \mathrm{h}\end{array}$ & $\begin{array}{l}\text { - peroxidação de } \\
\text { lipidios (MDA) } \\
\text { - TAS }\end{array}$ & $\begin{array}{l}\text { Em jejum, (entre } \\
9: 00 \text { e } 9: 30 \text { da } \\
\text { manhã) } \\
30 \text { min antes do } \\
\text { exercicio e } 3,15 \\
\text { e } 60 \text { minutos } \\
\text { durante.s. }\end{array}$ & $\begin{array}{l}\text { MDA- } \uparrow \text { menor no } \\
\text { GM em } 15 \text { min e em } \\
60 \text { min de exercicio } \\
\text { TSA- valores similares } \\
\text { ao basal com } 3 \text { e } 15 \\
\text { min exercicio, } \uparrow \uparrow \\
\text { significativamente com } \\
60 \text { min de exercicio. }\end{array}$ \\
\hline $\begin{array}{l}\text { Ochoa JJ } \\
\text { et al., 2011(1) }\end{array}$ & $\begin{array}{l}\text { Artigo Original } \\
\text { Randomizado } \\
\text { duplo cego }\end{array}$ & $\begin{array}{l}20 \text { Atletas } \\
\text { amadores de ultra } \\
\text { endurance }\end{array}$ & $\begin{array}{l}-10 \mathrm{GM} \\
3 \mathrm{mg} 2 \text { dias antes, } 3 \\
\mathrm{mg} 3 \mathrm{X} \text { na véspera } \mathrm{e} \\
3 \mathrm{mg} 1 \mathrm{~h} \text { antes do } \\
\text { teste. } \\
-10 \mathrm{GC} \text { placebo }\end{array}$ & $\begin{array}{l}\text { Exercicio intenso, } \\
\text { corrida de } \\
\text { montanha e ultra } \\
\text { endurance } \\
50 \mathrm{~km} \text { de } \\
\text { distância em } \\
\text { inclinaçăo desde } \\
\text { altitude } 640 \mathrm{~m} \text { até } \\
3393 \mathrm{~m}\end{array}$ & $\begin{array}{l}\text { Sangue } \\
\text { TAS, GPx, CAT } \\
\text { Urina } \\
\text { Isoprostanos, } \\
\text { 8-OHdG }\end{array}$ & $\begin{array}{l}\text { Sangue antes e } \\
\text { imediatamente } \\
\text { após o teste } \\
\text { urina antes e } \\
\text { imediatamente } \\
\text { após o teste. }\end{array}$ & $\begin{array}{l}\uparrow \text { melatonina após } \\
\text { administração } \\
\text { comparado com o GC } \\
\uparrow \mathrm{CAT}, \mathrm{GPx} \text { no GM } \\
\text { após exercicio, } \\
\uparrow \text { TAS antes e após o } \\
\text { exercicio. } \\
\uparrow 8-\mathrm{OHdG} \text { e } \\
\text { isoprostanos para GC } \\
\text { e GM }\end{array}$ \\
\hline $\begin{array}{l}\text { Mero A et al., } \\
2006(10)\end{array}$ & $\begin{array}{l}\text { Artigo Original } \\
\text { Randomizado } \\
\text { duplo cego }\end{array}$ & $\begin{array}{l}10 \text { indivíduos } \\
\text { saudáveis }\end{array}$ & $\begin{array}{l}\text {-Duas ocasiöes: } \\
\text { o mesmo grupo } \\
\text { recebia } 6 \text { mg } \\
\text { melatonina } 60 \text { min } \\
\text { antes do exercicio e } \\
\text { em outra ocasiāo } \\
\text { recebia placebo. }\end{array}$ & $\begin{array}{l}-80 \text { min de } \\
\text { exercício pesado } \\
\text { de resistência. }\end{array}$ & $\begin{array}{l}\text { Melatonina } \\
\text { plasmática }\end{array}$ & $\begin{array}{l}\text { Em jejum, } 60^{\prime} \text { e } \\
\text { imediatamente } \\
\text { antes do } \\
\text { exercicio } \\
\text { durante, e após } \\
0^{\prime}, 15^{\prime}, 30^{\prime} \text { e } 60^{\prime} \text {. }\end{array}$ & $\begin{array}{l}\text { O grupo que recebeu } \\
\text { a suplementação } \\
\text { apresentou maiores } \\
\text { elevações de } \\
\text { malatonina no sangue } \\
\text { antes do exercício e } \\
\text { em todas as } \\
\text { mensuraçōes durante } \\
\text { e após o teste. }\end{array}$ \\
\hline
\end{tabular}

GC- Grupo Controle / GM -Grupo que recebeu a melatonina / MDA- malondialdeído / TAS- total antioxidant status (estado total de antioxidantes) - kit comercial / GPX - glutationa peroxidase/ CAT - catalase / 8-OHdG - 8 hidróxi-2-desoxiguanosina-: marcador de dano oxidativo.

\footnotetext{
${ }^{\S}$ Autor correspondente: Claudia Coutinho-e-mail: dra.claudiacoutinho@gmail.com. Afiliações: ${ }^{1}$ Escola de Educação Física do Exército; ${ }^{2}$ Instituto Federal de Educação, Ciência e Tecnologia do Rio Grande do Sul (IFRS/RS/Brasil).
} 
Tabela 2 - Estudos em modelo animal

\begin{tabular}{|c|c|c|c|c|c|c|}
\hline Auto e ano & Amostra & $\begin{array}{l}\text { Tipo de suplemen- } \\
\text { tação }\end{array}$ & Estimulo oxidativo & $\begin{array}{l}\text { Parâme-tros do } \\
\text { estresse oxidativo }\end{array}$ & Coleta & Resultados \\
\hline $\begin{array}{l}\text { Mauriz L et al. } \\
2007(10)\end{array}$ & $\begin{array}{l}\text { Ratos Wistar machos } \\
\text { divididos em } 4 \text { grupos } \\
\text { (n=8) j- ratos jovens de } 3 \\
\text { meses não sup* } \\
\text {-ratos idosos de } 24 \\
\text { meses năo sup* } \\
\text {-ratos jovens sup* } \\
\text {-ratos idosos sup* }\end{array}$ & $\begin{array}{l}\text { Melatonina } 20 \mathrm{mg} / 1 \\
\text { de água por quatro } \\
\text { semanas }\end{array}$ & $\begin{array}{l}\text { Envelhecimento } \\
\text { como fator pró- } \\
\text { oxidativo }\end{array}$ & $\begin{array}{l}\text { TBARS no fígado e } \\
\text { GSSG/GSH } \\
\text { CAT, GPX, SOD }\end{array}$ & $\begin{array}{l}\text { Após sacri- } \\
\text { ficados } \\
\text { coleta-do o } \\
\text { fígado e } \\
\text { centrifugado } \\
\text { para isola- } \\
\text { mento de } \\
\text { proteinas } \\
\text { mito-condriais }\end{array}$ & $\begin{array}{l}\text { - nos ratos idosos sup com } \\
\text { melatonina, razăo GSSG } \\
\text { GSH foi semelhante aos } \\
\text { jovens. } \\
\text { - ratos sup com melatonina } \\
\text { mantiveram seus niveis } \\
\text { de SOD, GPx, (citosólico } \\
\text { e mitocondrial) e CAT } \uparrow \\
\text { ao contrário dos ratos } \\
\text { idosos nāo } \\
\text { suplementados. }\end{array}$ \\
\hline $\begin{array}{l}\text { Veneroso C } \\
\text { et al., 2009(21) }\end{array}$ & $\begin{array}{l}200 \mathrm{~g} \pm 10 \text { de ratos } \\
\text { Wistar machos divididos } \\
\text { em } 4 \text { grupos: } \mathrm{GC} / \mathrm{GC} \\
\text { tratado com mel**/Grupo } \\
\text { do exercicio/Grupo do } \\
\text { exercicio tratado com } \\
\text { mel** }\end{array}$ & $\begin{array}{l}\text { melatonina } \\
\text { intraperito-neal na } \\
\text { dose de } 1.0 \mathrm{mg} / \mathrm{kg} \\
\text { de peso corporal } 30 \\
\text { min antes do } \\
\text { exercicio. }\end{array}$ & $\begin{array}{l}60 \text { min na esteira } \\
\text { numa velocidade de } \\
25 \mathrm{~m} / \text { min e } \\
\text { inclinaçăo de } 10 \%\end{array}$ & $\begin{array}{l}\text { atividade da } \\
\text { mielope-roxidase e } \\
\text { oxido nitrico } \\
\text { sintetase }\end{array}$ & $\begin{array}{l}2 \text { hs após } \\
\text { exercicio, } \\
\text {-sangue da } \\
\text { aorta } \\
\text { abdominal } \\
\text { estocado o } \\
\text { plasma } \\
\text {-músculo } \\
\text { cardiaco } \\
\text { medidas } \\
\text { realizadas na } \\
\text { fração } \\
\text { citosólica. }\end{array}$ & $\begin{array}{l}-\uparrow \text { da MPO nos ratos } \\
\text { exercitados comparado } \\
\text { com o controle, mas năo se } \\
\text { alterou nos ratos } \\
\text { exercitados tratados com } \\
\text { melatonina. }\end{array}$ \\
\hline $\begin{array}{l}\text { Baydas G et al., } \\
2005(23)\end{array}$ & $\begin{array}{l}30 \text { ratos jovens ( } 3 \\
\text { meses) } \\
\text { - } 30 \text { ratos idosos (19 } \\
\text { meses) todos machos } \\
\text { Wistar albinos. } \\
\text { - Divididos em } 3 \\
\text { grupos. }\end{array}$ & $\begin{array}{l}\text { Um dos grupos do } \\
\text { etanol, recebeu } \\
\text { melatonina } 10 \mathrm{mg} / \mathrm{kg} \\
\text { por } 45 \text { dias. }\end{array}$ & $\begin{array}{l}\text { um grupo } \\
\text { recebeu salina } \\
\text { intraperitoneal } \\
\text { os outros } 2 \\
\text { grupos } \\
\text { receberam etanol } \\
\text { intraperitoneal } 2 \\
\mathrm{~g} / \mathrm{kg} \text { durante } 45 \\
\text { dias. }\end{array}$ & $\begin{array}{l}\text { Peroxidaçăo lipidica } \\
\text { MDA e 4-HDA (LPO } \\
586 \text { ) e glutationa no } \\
\text { hipocampo e córtex }\end{array}$ & $\begin{array}{l}\text { Decapitados e } \\
\text { extraido o } \\
\text { cérebro. }\end{array}$ & $\begin{array}{l}\text { - Nos ratos idosos: } \\
\uparrow \text { LPO e } \downarrow \text { GSH } \\
\text {-no grupos etanol } \uparrow \text { LPO e } \\
\downarrow \text { GSH no cérebro dos } \\
\text { ratos jovens e idosos } \\
\downarrow \text { LPO no tecido cerebral } \\
\text { com a repetição na sup de } \\
\text { melatonina } \\
\uparrow G S H \text { no hipocampo e } \\
\text { córtex no GM } \\
\text { No grupo jovem, a mel teve } \\
\text { menor efeito inibitório no } \\
\text { LPO. }\end{array}$ \\
\hline
\end{tabular}

TBARS- substâncias reativas de tiobarbitúricos - índice de peroxidação lipídica / GSSG/ GH - Razão glutationa oxidada e glutationa reduzida/ GPX glutationa peroxidase / CAT - catalase/ MPO- mieloperoxidase /LPO - LPO 586 kit comercial para mensurar de MDA (malonaldeído) e 4-HDA (4hydroxilalquenals).

*sup - suplementados; **mel- melatonina.

Estudos indicam o aumento da concentração plasmática de melatonina durante e após o exercício físico, provavelmente pela demanda antioxidante(9). Durante uma competição de ciclismo de quatro dias, foi dosado no sangue e na urina a concentração de melatonina e seu metabólito (6-sulfatoximelatonina) antes e depois da competição. Foi demonstrado um aumento estatisticamente significativo da concentração de melatonina no plasma e na excreção de 6sulfatoximelatonina na urina após a competição, pelo simples estímulo do exercício intenso(9).

Em um estudo com modelo animal, a suplementação de melatonina na água a $4 \mathrm{mg} / \mathrm{l}$ produziu um aumento da concentração plasmática de melatonina, mensurada no período noturno, 15 vezes maior do que em animais não suplementados. $O$ fato da melatonina exógena provocar aumento em sua concentração sérica, e não apenas induzida por fatores oxidativos ou inflamatórios, sugere a eficácia da suplementação(10).

A suplementação de melatonina promove um aumento significativo da sua concentração plasmática, aumentando a oferta deste hormônio para a célula muscular esquelética e cardíaca. Mero et al.(12), em estudo de modelo humano, observaram que a suplementação com $6 \mathrm{mg}$ de melatonina 60 minutos antes do exercício intenso de resistência provocou um aumento nos níveis séricos de melatonina significativamente maior no grupo suplementado do que no grupo que recebeu placebo, antes, durante e após o exercício. O pico de elevação máxima foi após 60 minutos da suplementação, ou seja, imediatamente antes do início do exercício físico(12).

Todos os estudos realizados em modelo humano, que relacionaram a suplementação de melatonina com exercício físico, demonstraram que a suplementação de 
melatonina aumentou a oferta de vários marcadores da redução exigidos pela célula, em resposta ao estímulo nocivo dos radicais livres $(1,3,12)$. Esses resultados podem ser explicados pelo fenômeno da hormese. Hormese é o termo que, transliterado do inglês hormesis, refere-se a uma exposição repetida de um determinado agente tóxico que leva uma adaptação do organismo ativando seu sistema de defesa. No caso, a célula do músculo esquelético e cardíaco possuem uma grande adaptabilidade ao exercício físico agudamente e ao treinamento crônico, através da competência do sistema antioxidante e metabolicamente através do remodelamento da mitocôndria(13). Nesse sentido, a produção de reactive oxygen and nitrogen species (RONS - espécies reativos de oxigênio e nitrogênio) leva a um estímulo para a adaptação hormética, servindo como moléculas sinalizadoras para a via redutora.

No estudo de Maldonado et al.(3) um grupo de jogadores profissionais de futebol, plausivelmente adaptados ao estresse oxidativo, foi suplementado com $6 \mathrm{mg}$ de melatonina ou placebo antes do exercício físico (Tabela 1). O exercício intenso levou a um aumento da peroxidação lipídica com um aumento do malondialdeído (MDA) no plasma(3). Indicador da peroxidação lipídica, o MDA é um parâmetro do ataque aos lipídios que, dentre os componentes celulares, são os mais visados pelos radicais livres(4). Os atletas que foram suplementados com $6 \mathrm{mg}$ de melatonina antes do exercício intenso sofreram uma redução significativa no aumento deste subproduto, durante 15 e 60 minutos de exercício intenso. Nesses atletas, a suplementação de melatonina mostrou benefício na redução da peroxidação lipídica. Também obtiveram um aumento estatisticamente significativo do estado total de antioxidantes (TAS - Total Antioxidant Status) após 60 minutos de exercício, enquanto que o grupo não suplementado sofreu uma diminuição dessa capacidade após 15 e 60 minutos de exercício. O TAS é um dos marcadores da defesa antioxidante da célula, é um kit comercializado que mensura o quanto uma amostra de sangue ou tecido resiste a radicais livres in vitro(14). Os resultados desse estudo em jogadores de futebol demonstraram que a suplementação de melatonina antes de exercício intenso diminuiu o estresse oxidativo e aumentou o estado total de antioxidantes. Os autores concluíram que a suplementação com melatonina pode ser benéfica na recuperação de atletas profissionais, apesar de serem adaptados para aguentar uma determinada quantidade de radicais livres, a exposição prolongada acima deste limite pode levar a efeitos deletérios na saúde desses atletas(3).

$\mathrm{O}$ aumento da oferta antioxidante na célula muscular promove proteção contra-ataques oxidativos, assim, reduzindo a fadiga $(15,16)$. Desta maneira, é plausível que a melatonina, por sua potente ação de varredura dos reactive oxygen species (ROS - espécies reativas de oxigênio), pode reduzir a fadiga muscular melhorando a performance no exercício(17).

No estudo de Ochoa et al.(1), atletas amadores bem treinados foram suplementados com melatonina, de dois dias até uma hora antes da realização de exercício de ultraendurance (alta resistência e longa duração) de corrida em montanha(1). Houve um aumento significativo do nível plasmático de melatonina no grupo que foi suplementado quando comparado ao grupo controle. $\mathrm{O}$ estado total de antioxidantes, a glutamato peroxidase e a catalase, também aumentaram significativamente no plasma do grupo que recebeu a melatonina quando comparado ao grupo controle, onde quase não houve mudança, após o teste. Além destes, foi observado um aumento da 8-hidroxi 2desoxiguanosina (8-OhdG) e isoprostanos urinários. A 8-OhdG urinaria é um marcador da oxidação do ácido desoxirribonucleico (DNA - deoxyribonucleic acid) em resposta aos radicais livres e o isoprostano é um marcador da peroxidação lipídica. A suplementação de melatonina antes do exercício mostrou-se benéfica, pois, além de atuar como antioxidante, promove aumento da oferta de antioxidantes naturais da célula, como SOD, catalase e GPX(1). Esse estudo demonstrou que a suplementação com melatonina aumenta a capacidade antioxidativa do plasma, quando comparado com o grupo controle, o que pode ser uma ferramenta de ajuda importante na recuperação de atletas, uma vez que estão 
mais expostos ao dano oxidativo relacionado às altas cargas de treinamento físico.

No estudo de Mero et al.(12), 10 indivíduos saudáveis em uma determinada ocasião recebiam melatonina 60 minutos antes do teste e em outra, placebo. Esse estudo demonstrou uma elevação dos níveis séricos de melatonina em ambos os casos, durante e após o teste, sendo que esse efeito foi maior no grupo suplementado $(\mathrm{p}<0,05)(12)$.

Radicais livres, em pequenas quantidades, induzem a defesa antioxidante através da expressão de enzimas antioxidantes; dentro do conceito de hormese, há uma sinalização estimulatória da defesa antioxidante a partir de baixas concentrações de RONS, enquanto que uma alta concentração produz um efeito inibitório(18).

A produção de força pelo músculo depende da produção dos ROS, como bem estabelecido pela literatura $(6,19)$. Um pequeno aumento na produção de ROS leva a um incremento na produção de força pelo músculo esquelético, porém aumentos maiores levam à diminuição da força, ocasionando a fadiga muscular, no caso de exercícios extenuantes e de longa duração(4).

Os estudos em modelo animal (Tabela 2) investigaram outros parâmetros de estresse oxidativo por estímulos diferentes. Mauriz et al.(10) utilizaram como provocador da oxidação, o envelhecimento. Sabe-se que com o tempo, o organismo torna-se menos eficiente para lidar com o estresse oxidativo. A produção de enzimas antioxidantes da defesa celular encontra-se diminuída, e há um declínio fisiológico que pode estar relacionado ao dano provocado continuamente pelos oxidantes endógenos(20). No estudo analisado, a relação glutationa oxidada sobre glutationa reduzida (GSSD/GSH) e o TBARS (substâncias reativas de fenobarbitúricos), que são subprodutos da peroxidação lipídica detectadas utilizando o ácido tiobarbitúrico como reagente, in vitro, foi $20 \%$ e $58 \%$ maior nos ratos idosos, respectivamente, quando comparado com animais jovens, sendo que este aumento foi corrigido com a suplementação de melatonina(10). As enzimas GPX e a SOD mantiveram sua produção semelhante no grupo de ratos idosos suplementados com melatonina em relação ao grupo de animais jovens não suplementados, enquanto que a catalase aumentou significativamente nos ratos suplementados. Esse resultado apoia o fato da melatonina ser capaz de regular e manter a produção de enzimas antioxidantes como GSH, SOD, e catalase, evitando o excesso de produtos da peroxidação lipídica provocada pelos radicais livres.

Veneroso et al.(21) utilizaram exercício físico como fator oxidativo, dosando no músculo cardíaco a mieloperoxidase (MPO) duas horas após o teste. Os níveis de MPO aumentaram significativamente nos ratos exercitados sem a suplementação de melatonina, enquanto nos ratos suplementados que realizaram o esforço físico, a concentração de MPO se manteve semelhante ao grupo controle que não se exercitou (21). A MPO está relacionada com a formação de ROS, e contribui para o processo aterogênico na evolução da doença coronariana (22).

No terceiro estudo em modelo animal analisado, o gatilho pró oxidativo é o etanol, e o tecido de mensuração dos marcadores oxidativos é o cérebro. A concentração do GSH diminuiu e o MDA aumentou nos ratos idosos do grupo controle, e nos jovens e idosos do grupo que recebeu o etanol. Esse efeito foi anulado com a suplementação repetida de melatonina, tanto nos jovens como nos idosos, sendo que o efeito inibitório foi menor nos ratos jovens(23). A administração de melatonina foi capaz de reduzir significativamente $\mathrm{o}$ aumento do MDA induzido pelo etanol e de aumentar a concentração de GSH, neutralizando o dano oxidativo causado pelo álcool, e melhorando a plasticidade neural, sendo que esta melhora foi mais evidente nos ratos idosos do que nos jovens.

Existe controvérsia na literatura quanto ao benefício da suplementação de antioxidantes em geral. Nem todas as evidências apontam para uma melhora no dano mitocondrial e na fadiga muscular através da suplementação de antioxidantes, embora seja consenso que esta suplementação reduz os marcadores de stress oxidativo induzidos pelo exercício físico(4). Porém, consta documentado, tanto através de 
estudo em humanos como em modelo animal, que o uso de antioxidantes varredores de RONS pode retardar a instalação de fadiga(6).

Há críticas em relação ao real benefício da suplementação com antioxidantes, principalmente porque os testes são realizados utilizando reagentes laboratoriais para mensuração dos marcadores do estresse oxidativo(24). Estudos utilizando especificamente a melatonina como antioxidante no exercício físico ainda são muito poucos, apesar de indicarem um benefício promissor.

\section{Pontos fortes e limitações do estudo}

Um ponto forte do estudo foi a própria investigação de um assunto ainda pouco explorado na literatura, sendo que os resultados contribuíram para ressaltar $\mathrm{o}$ quanto ainda há que se investigar.

Uma das limitações do estudo foi a busca somente em duas bases, o que pode ter limitado a possibilidade de se identificar outros estudos. Entretanto, as bases utilizadas estão entre as mais importantes na área da saúde humana.

Outra limitação de estudo foi considerar o período de tempo somente a partir do ano 2000, entretanto, avalia-se que um período de 16 anos é apropriado para se investigar na literatura o conhecimento mais recente.

\section{Conclusão}

Foram identificados poucos estudos relacionando a suplementação de melatonina com a melhora do estresse oxidativo induzido pelo exercício. Os resultados do presente estudo indicam que os efeitos da suplementação de melatonina são promissores quanto aos benefícios na prática de exercício físico.

O hormônio melatonina está envolvido em uma serie de regulações em todo organismo, tendo uma penetração fácil em todos os tecidos pela sua qualidade ambifílica e, ainda, após a administração oral, seus níveis plasmáticos aumentam significativamente o que é animador, no que diz respeito à sua absorção intacta pelo sistema digestivo. A melatonina tem um papel chave no estresse oxidativo muscular, não só por sua ação antioxidante amplificada, mas pela modulação na produção de outras enzimas antioxidantes presentes na célula. Trata-se de uma substância sem toxicidade, e, portanto, uma promessa no campo da suplementação saudável que pode atuar beneficiando o desempenho e preservando a saúde dos atletas.

A lacuna no conhecimento é evidente, por conseguinte, sugere-se que sejam conduzidos estudos longitudinais, com duração de, pelo menos, seis meses, utilizando a suplementação de melatonina antes do treinamento físico. Esse tipo de desenho de estudo é necessário para que as adaptações do organismo possam ser observadas e inferências causais possam ser formuladas quanto aos efeitos da melatonina exógena na atenuação do dano oxidativo. Além disso, sugere-se que os estudos futuros incluam em suas análises a associação da melhora do dano oxidativo com avaliações de bem-estar, melhora no desempenho e na redução nos indicadores de fadiga.

\section{Declaração de conflito de interesses}

Não há nenhum conflito de interesses em relação ao presente estudo.

\section{Declaração de financiamento}

O presente estudo foi conduzido sem financiamento.

\section{Referências}

1. Ochoa JJ, Díaz-Castro J, Kajarabille N, García C, Guisado IM, De Teresa C, et al. Melatonin supplementation ameliorates oxidative stress and inflammatory signaling induced by strenuous exercise in adult human males. Journal of Pineal Research. [Online] 2011;51(4): 373-380. Available from: doi:10.1111/j.1600079X.2011.00899.x

2. Jones DP. Redefining oxidative stress. Antioxidants \& Redox Signaling. [Online] 2006;8(9-10): 1865-1879. Available from: doi:10.1089/ars.2006.8.1865

3. Maldonado MD, Manfredi M, Ribas-Serna J, Garcia-Moreno H, Calvo JR. Melatonin administrated immediately before an intense exercise reverses oxidative stress, improves immunological defenses and lipid metabolism in football players. 
Physiology \& Behavior. [Online] 2012;105(5): 1099-1103. Available from: doi:10.1016/j.physbeh.2011.12.015

4. Powers SK, Jackson MJ. Exercise-induced oxidative stress: cellular mechanisms and impact on muscle force production. Physiological Reviews. [Online] 2008;88(4): 1243-1276. Available from: doi:10.1152/physrev.00031.2007

5. Macchi MM, Bruce JN. Human pineal physiology and functional significance of melatonin. Frontiers in Neuroendocrinology. [Online] 2004;25(34): 177-195. Available from: doi:10.1016/j.yfrne.2004.08.001

6. Escames G, Ozturk G, Baño-Otálora B, Pozo MJ, Madrid JA, Reiter RJ, et al. Exercise and melatonin in humans: reciprocal benefits. Journal of Pineal Research. [Online] 2012;52(1): 1-11. Available from: doi:10.1111/j.1600079X.2011.00924.X

7. Berhouma M. Beyond the pineal gland assumption: a neuroanatomical appraisal of dualism in Descartes' philosophy. Clinical Neurology and Neurosurgery. [Online] 2013;115(9): 1661-1670. Available from: doi:10.1016/j.clineuro.2013.02.023

8. Reiter RJ, Paredes SD, Manchester LC, Tan D-X. Reducing oxidative/nitrosative stress: a newly-discovered genre for melatonin. Critical Reviews in Biochemistry and Molecular Biology. [Online] 2009;44(4): 175-200. Available from: doi:10.1080/10409230903044914

9. Serrano E, Venegas C, Escames G, Sánchez-Muñoz C, Zabala M, Puertas A, et al. Antioxidant defence and inflammatory response in professional road cyclists during a 4-day competition. Journal of Sports Sciences. [Online] 2010;28(10): 1047-1056. Available from: doi:10.1080/02640414.2010.484067

10. Mauriz JL, Molpeceres V, GarcíaMediavilla MV, González P, Barrio JP, González-Gallego J. Melatonin prevents oxidative stress and changes in antioxidant enzyme expression and activity in the liver of aging rats. Journal of Pineal Research.
[Online] 2007;42(3): 222-230. Available from: 079X.2006.00409.X

11. Jones DP. Redefining oxidative stress. Antioxidants \& Redox Signaling. [Online] 2006;8(9-10): 1865-1879. Available from: doi:10.1089/ars.2006.8.1865

12. Mero AA, Vähälummukka M, Hulmi JJ, Kallio P, von Wright A. Effects of resistance exercise session after oral ingestion of melatonin on physiological and performance responses of adult men. European Journal of Applied Physiology. [Online] 2006;96(6): 729-739. Available from: doi:10.1007/s00421-005-0119-z

13. Ji LL, Gomez-Cabrera M-C, Vina J. Exercise and hormesis: activation of cellular antioxidant signaling pathway. Annals of the New York Academy of Sciences. [Online] 2006;1067: 425-435. Available from: doi:10.1196/annals.1354.061

14. Jackson MJ. The Handbook of Oxidants and Antioxidants in Exercise.. 1st Edition. C. Sen L. Packer O. Hänninen. Elsevier Science Published; 2000. 57-68 p.

15. Matuszczak Y, Farid M, Jones J, Lansdowne S, Smith MA, Taylor AA, et al. Effects of $\mathrm{N}$-acetylcysteine on glutathione oxidation and fatigue during handgrip exercise. Muscle \& Nerve. [Online] 2005;32(5): 633-638. Available from: doi:10.1002/mus.20385

16. Gomez-Cabrera M-C, Viña J, Ji LL. Interplay of oxidants and antioxidants during exercise: implications for muscle health. The Physician and Sportsmedicine. [Online] 2009;37(4): 116-123. Available from: doi:10.3810/psm.2009.12.1749

17. Tan D-X, Manchester LC, Terron MP, Flores LJ, Reiter RJ. One molecule, many derivatives: a never-ending interaction of melatonin with reactive oxygen and nitrogen species? Journal of Pineal Research. [Online] 2007;42(1): 28-42. Available from: doi:10.1111/j.1600079X.2006.00407.x

18. Calabrese EJ, Baldwin LA. Hormesis: the dose-response revolution. Annual Review 
of Pharmacology and Toxicology. [Online] 2003;43: 175-197. Available from: doi:10.1146/annurev.pharmtox.43.100901. 140223

19. Reid MB. Invited Review: redox modulation of skeletal muscle contraction: what we know and what we don't. Journal of Applied Physiology (Bethesda, Md.: 1985). 2001;90(2): 724-731.

20. Stadtman ER. Protein oxidation and aging. Science (New York, N.Y.). 1992;257(5074): 1220-1224.

21. Veneroso C, Tuñón MJ, GonzálezGallego J, Collado PS. Melatonin reduces cardiac inflammatory injury induced by acute exercise. Journal of Pineal Research. [Online] 2009;47(2): 184-191. Available from: doi:10.1111/j.1600079X.2009.00699.X

22. Roman RR, Wendland AE, Polanczyk C A. Mieloperoxidase e doença arterial coronariana: da pesquisa à prática clínica. Arquivos Brasileiros de Cardiologia. 2008;91(1):e12-e19.

https://dx.doi.org/10.1590/S0066782X2008001300015.

23. Baydas G, Yasar A, Tuzcu M. Comparison of the impact of melatonin on chronic ethanol-induced learning and memory impairment between young and aged rats. Journal of Pineal Research. [Online] 2005;39(4): 346-352. Available from: doi:10.1111/j.1600079X.2005.00257.X

24. B Halliwell, JMC Gutteridge. Free radicals in biology and medicine. 5th Edition. Oxford University Press; 2015. 